Proceedings

\title{
Asian Citrus Psyllid Feeding Behavior in Citrus Treated with Specific and Non-Specific dsRNA ${ }^{+}$
}

\author{
Jonatha dos Santos Silva ${ }^{1, *}$, Eduardo Chumbinho de Andrade ${ }^{2}$ and Wayne Hunter ${ }^{3}$ \\ 1 Federal University of Reconcavo of Bahia (UFRB) \\ 2 Brazilian Agricultural Research Corporation (Embrapa); eduardo.andrade@embrapa.br \\ 3 Horticultural Research Laboratory (USDA-ARS); wayne.hunter@usda.gov \\ * Correspondence: Jonatha0327@gmail.com \\ + Presented at the 1st International Electronic Conference on Entomology (IECE 2021), 1-15 July 2021; \\ Available online: https://iece.sciforum.net/.
}

Citation: dos Santos Silva, J.; de Andrade, E.C.; Hunter, W. Asian Citrus Psyllid Feeding Behavior in Citrus Treated with Specific and Non-Specific dsRNA, in Proceedings of the 1st International Electronic Conference on Entomology, 1-15 July 2021, MDPI: Basel, Switzerland, doi:10.3390/IECE-10510

Published: 1 July 2021

Publisher's Note: MDPI stays neutral with regard to jurisdictional claims in published maps and institutional affiliations.

Copyright: (c) 2021 by the authors. Submitted for possible open access publication under the terms and conditions of the Creative Commons Attribution (CC BY) license (http://creativecommons.org/licenses /by/4.0/).

\begin{abstract}
The potential of RNA interference (RNAi) technology to control the Asian Citrus psyllid $(\mathrm{ACP})$, vector of Huanglongbing (HLB), has been demonstrated in different publications. RNAi is a natural biological process that specifically down regulates the expression of a specific gene, being more environmentally friendly approach to control insects. We're interested to understand if the treatment of a plant with dsRNA could induce an ACP response. To evaluate if ACP sense the presence of a dsRNA (ACP-specific and non-specific) in plants, we set up free of choice experiments to examined psyllid response to dsRNA treated plants versus non-treated plants, to dsRNA-specific versus dsRNA non-specific and plants treated with two dsRNA-specific. Four groups of 4 plant flush each ( 2 of each treatment) were placed in each corner of a cage, and 50 ACP were release at the center. They were observed for $15 \mathrm{~d}$, and the number of ACP on each flush recorded daily. Each experiment was repeated at least four times. No significant differences, using F-test analyses, was observed in ACP feeding preferences regarding the presence of dsRNA $(p<0,05)$. These preliminary results suggest that psyllids appear not to be sensitive to dsRNA ingestion, as they may be for traditional chemical insecticides, thus were not repelled.
\end{abstract}

Keywords: Diaphorina citri; Huanglongbing; RNA interference

\section{Introduction}

Citriculture is one of the sectors of great importance for agriculture. In 2019, the world production of orange reached values of approximately 74.7 million tons. Brazil stands out among the main citrus producers, and in this same year, contributes with about $21.7 \%$ of global production [1,2]. Like other sectors, citrus production faces a series of phytosanitary problems that limit its production. Due to the difficulties of control and economic impact, the Huanglongbing (HLB) or citrus greening is considered the most devastating disease in the citrus industry worldwide. [3,4].

HLB is caused by gram-negative bacteria belonging to the genus Candidatus Liberibacter (Ca. L.), with three species reported: Candidatus Liberibacter asiaticus (CLas), Candidatus Liberibacter africanus (CLaf) e Candidatus Liberibacter americanus (CLam) [3-6]. In the field, transmission can be done by two species of psyllids; Trioza erytreae (Del Guercio) (Hemiptera; Psyllidae), (Hemiptera; Psyllidae) and Diaphorina citri (Kuwayama) (Hemiptera; Psyllidae). [3,5,7]. D. citri, well known as Asian citrus psyllid (ACP), is considered the main vector of HLB due to its wide distribution in the main citrus production centers in Asia and America [3,4,6].

Control of $D$. citri is based on the use of synthetic pesticides. Producers have a wide variety of these chemicals available, whether they have a contact or systemic action. However, the intensive use of pesticides and the low selectivity of these agrochemicals favors 
the emergence of resistant populations and increased environmental impact [21-23]. Thus, there is a need to develop new control strategies that are efficient and environmentally sustainable. Genetic strategies for crop protection have been studied over the past few years and have shown to be highly promising. The RNA interference (RNAi), discovered in the early 1990s, has shown great potential to be used as an efficient tool for pest control.

RNAi is a natural mechanism that occurs in eukaryotic cells, and is involved in gene regulation and antiviral defense. It is activated by double-stranded RNA molecule (dsRNA) (the trigger molecule), which can be expressed or introduced into the cell [8]. The specificity of the dsRNA sequence allows for the possibility of silencing genes that are essential to the survival of a specific specie. [9].

The use of RNAi technology for sucking insects, such as Hemipteras, requires that dsRNA molecules must be present in the vascular system of plants, which represents one of the main challenges for the efficient control of these insects [10]. Despite this apparent difficulty, Andrade and Hunter [12] observed D. citri mortality rates of up to $56 \%$ when insect fed on shoots treated with a dsRNA homologous to the Argenine kinase gene, demonstrating the feasibility of use RNAi to control sucking insects.

With the advance of the technology towards the development of RNAi-based products, some questions still need to me answered. One of these issues is related to the ability of insects to sense the presence of dsRNA in a plant, and thus avoid feeding on it. To address this question, the present work aims to evaluate whether the presence of dsRNA can act as attractive or repellent, and change the host selection behavior of the psyllid.

\section{Methods}

\subsection{Plant Material and Insect Colony}

The citrus shoots were obtained from sweet orange seedlings (cv. Valencia) (Citrus sinensis (L.)) kept in a greenhouse. The ACP colony was reared on Murraya paniculata, in laboratory at $25{ }^{\circ} \mathrm{C}$ and photoperiod of $16 \mathrm{~h} / 8 \mathrm{~h}$ (light/dark). Adult psyllids of ca. 5 days post eclosion were used for the experiments

\subsection{Bioassay}

The shoots were collected and sanitized in a 5\% sodium hypochlorite solution for 10 minutes, and then rinsed three times in distilled water. With a blade (scalpel), the excess leaves were removed, leaving only the three youngest leaves. The base of the stem was cut at an angle of $45^{\circ}$, and the shoots were patterned to approximately $10 \mathrm{~cm}$ in length. Then, the shoots were transferred to $1.5 \mathrm{~mL}$ microtubes containing $0.5 \mathrm{~mL}$ of the $1 \mathrm{ng} / \mu \mathrm{L}$ dsRNA solution or water. The opening of the microtube was sealed with Parafilm ${ }^{\circledR}$ " $\mathrm{M}$ ". After absorbing $90-95 \%$ of the solution (dsRNA or water), the tube was filled with water, and the shoots were transferred to racks, with four shoots being placed in each rack (2 shoots of each treatment). Four racks were arranged equidistantly inside a cage (BugDorm-2120 ${ }^{\circledR}$ ), and 50 adults of $D$. citri were released.

The cages were kept in a growth chamber, with a $12 \mathrm{~h} / 12 \mathrm{~h}$ photoperiod, temperature at $27{ }^{\circ} \mathrm{C}$ and $70 \%$ of average humidity. Three experiments were performed, one having ACP-specific dsRNA versus water (dsRNA-AK $\times$ Water), one with two ACP-specific dsRNAs (dsRNA-AK $\times$ dsRNA-Trehal) and another with ACP non-specific dsRNA versus water (dsRNA-GFP $\times$ Water). Each experiment was repeated at least four times.

Daily for 10 days, the number of psyllids in each shoot and the total number of insects in all shoots of each treatment were counted. At the end, the average number of insects that fed in each treatment was calculated. Data were submitted to double factorial analysis of variance (ANOVA) in a randomized block design $(p>0.05)$ using the $\mathrm{R}$ program.

\section{Results}

Free choice bioassays were established to assess whether the presence of dsRNA molecules in shoots could interfere with the feeding behavior of $D$. citri. Furthermore, it was 
also evaluated whether different dsRNA molecules present in the shoots can alter his feeding behavior.

The data obtained in the bioassays showed that the presence of dsRNA molecules in the shoots did not influence the feeding behavior of the psyllid. The average daily number of insects observed in shoots treated with psyllid-specific dsRNA (dsRNA-AK) was similar to that observed in shoots treated only with water during the entire bioassay period. (Figure 1A). A similar result was observed in bioassays that contained shoots treated with a psyllid non-specific dsRNA (dsRNA-GFP) (Figure 1B). The feeding behavior of the psyllid was not altered when the shoots were treated with two psyllid-specific dsRNA (dsRNA-Ak and dsRNA-Trehal) (Figure 1C). These observations were confirmed by statistical analysis, which shown no difference in the number of insects that fed on the shoots of both treatments in each bioassay (Table 1). These results demonstrate that the presence of dsRNA molecules in the plant does not influence the insect's choice behavior.

\subsection{Figures and Tables}

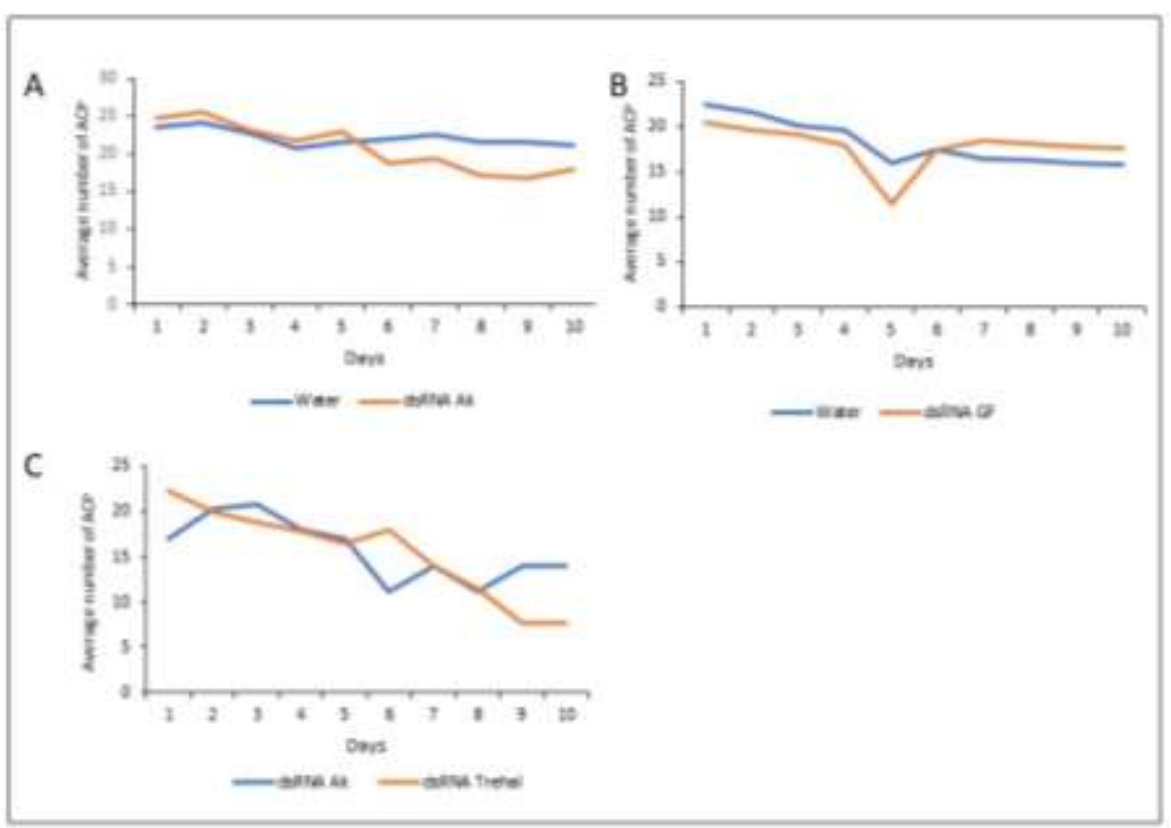

Figure 1. Feeding behavior of Diaphorina citri in shoots treated with dsRNA or water. Average daily number of insects per treatment over a ten-day period. (A) dsRNA-AK $x$ Water, (B) dsRNAAK $x$ dsRNA-Trehal, and $(\mathbf{C})$ dsRNA-GFP $\times$ Water.

Table 1. Results of analysis of variance (ANOVA) and comparison of means by the $\mathrm{F}$ test at $5 \%$ probability.

\begin{tabular}{ccccccc}
\hline \multicolumn{2}{c}{ Bioassay } & \multicolumn{2}{c}{ dsAk $\times$ Water } & \multicolumn{2}{c}{ dsAk $\times$ dsTrehal } & \multicolumn{2}{c}{ dsGF $\times$ Water } \\
\hline Average number of ACP & $20.86 a$ & $22.18 \mathrm{a}$ & $15.75 a$ & $15.43 a$ & $17.80 \mathrm{a}$ & $18.15 \mathrm{a}$ \\
\hline \multirow{2}{*}{$\mathrm{Pr}>\mathrm{Fc}$} & dsRNA & 0.14615 & 0.74474 & 0.51931 \\
\cline { 2 - 6 } & Days ${ }^{*}$ dsRNA & 0.59309 & 0.10058 & 0.09771 \\
\hline \multicolumn{2}{c}{ Coeficient of variation } & $26.39 \%$ & $28.5 \%$ & $19.06 \%$ \\
\hline
\end{tabular}

Means followed by the same letter are not statistically different.

\section{Discussion}

Host selection by D. citri can directly influence HLB transmission processes. The choice of a host derives from several factors and involves communication between the insect and the target plant. This communication occurs through chemical, olfactory, gustatory, visual signals, as well as the leaf tissue maturation stage. Patt et al. [20] showed in their study that even small changes in some of these stimuli can influence the behavioral 
response of D. citri. In the present work, it was observed that the presence of dsRNA molecules in citrus shoots does not interfere in the psyllid's host selection processes, indicating that these insects do not have the ability to perceive dsRNA in the shoots. It is important to point out that in the approach used in the free choice experiments, the dsRNA is absorbed by the shoots and therefore is not present on the leaf surface. However, it is likely that an RNAi-based product for psyllid control should be developed to be applied by foliar spray, and once on the leaf surface, the insect's response may be different, either by perceiving the dsRNA or some component of its formulation.

Another important observation is the insect mortality on bioassay between dsRNAAK and dsRNA-Trehal (data not shown). Insect mortality resulted in a constant decrease in the number of insects on each treatment, as observed in figure 3C. Overall mortality reached $56 \%$ after 10 days (data not shown). This is expected as either dsRNA-Ak as dsRNA-Trehal has been shown to cause significant psyllid mortality [12].

\section{Conclusions}

The experiments performed in the present work demonstrated that the presence of dsRNA molecules in citrus shoots, regardless of whether they are specific or not specific to the psyllid, did not alter its host selection behavior. These data indicate that the insect was not able to perceive the presence of the dsRNA in the shoots. In this sense, we can infer that there is no evidence that indicates attraction or repellency of the plant to D. citri due to the presence of dsRNA molecules.

\section{References}

1. FAO - Food and Agriculture Organization of the United Nations. Compare Data, 2020. Available online: http://www.fao.org/faostat/en/\#compare. Accessed on 22 February 2021.

2. USDA (United States Department of Agriculture). Citrus: World Markets and Trade. Global Agricultural Outlook Board. 2020, p. 1-13.

3. Bové, J.M. Huanglongbing: a destructive, newly-emerging, century-old disease of citrus. Journal of Plant Pathology. 2006, 88, 7-37.

4. Chavez, Y.; Chirinos, D.T.; González, G.; Lemos, N.; Fuentes, A.; Castro, R.; Kondo, T. Tamarixia radiata (Waterston) and Cheilomenes sexmaculata (Fabricius) as biological control agents of Diaphorina citri Kuwayama in Ecuador. Chil. J. Agric. Res. 2017, 77, 180-184.

5. Garnier, M.; Danel, N.; Bové, J.M. Etiology of citrus greening disease. Ann. de Microbiol 1984, 153, $169-179$.

6. Teixaira, D.C.; Saillard, C.; Eveillard, S.; Danet, J.L.; da Costa, P.I.; Ayres, A.J.; Bové J. 'Candidatus Liberibacter americanus', associated with citrus huanglongbing (greening disease) in São Paulo State, Brazil. Int. J. Syst. and Evol. Microbiol 2005, 55, 1857-1862.

7. Halbert, S. E.; Manjunath, K. L. Asian citrus psyllids (sternorrhyncha: Psyllidae) and greening disease of citrus: a literature review and assessment of risk in florida. Fla. Entomol. 2004, 87, 330-353.

8. Fire, A.Z.; Xu, S.; Montgomery, M.K.; Kostas, S.A.; Driver, S.E.; Mello C.C. Potent and specific genetic interference by double-strandedrnain Caenorhabditis elegans. Nature 1998, 391, 806-811.

9. Whyard, S.; Singh, A.D.; Wong, S. Ingested double-stranded RNAs can act as species-specific insecticides. Elsevier 2009, 39, 824-832.

10. Allen, M.L.; Walker, W.B. Saliva of Lygus lineolaris digests double stranded ribonucleic acids. J. Insect Physiol. 2012, 58, 391396.

11. Christiaens, O.; Smagghe, G. The challenge of RNAi-mediated control of hemipterans. Curr. Opin. in Insect Sci. 2014, 6, 1521.

12. Andrade, E.C.; Hunter, W.B. RNAi Feeding bioassay: development of a non-transgenic approach to control asian citrus psyllid and other hemipterans. Entomol. Exp. et Appl. 2017, 2, 389-396.

13. El-Shesheny, I. Hajeri, S.; El-Hawary, I.; Gowda, S.; Killiny, N. Silencing abnormal Wing Disc gene of the asian citrus psyllid, Diaphorina citri disrupts adult wing development and increases nymph mortality. PLoS ONE 2013, 8, 1-8.

14. Taning, C.N.T.; Andrade, E.C.; Hunter, W.B.; Christiaens, O.; Smagghe, G. Asian Citrus Psyllid RNAi Pathway - RNAi evidence. Sci. Rep. 2016, 6, 1-10.

15. Malik, H.J.; Raza, A.; Amin, I.; Scheffler, J.A.; Scheffler, B.E.; Brown, J.K.; Mansoor, S. RNAi-mediated mortality of the whitefly through transgenic expression of double-stranded RNA homologous to acetylcholinesterase and ecdysone receptor in tobacco plants. Sci. Rep. 2016, 6, 1-11. 
16. Rodrigues, T.B.; Dhandapani, R.K.; Duan, J.J.; Palli, S.R. RNA interference in the Asian Longhorned Beetle: Identification of Key RNAi Genes and Reference Genes for RT-qPCR. Sci. Rep. 2017, 7, 1-10.

17. Yu, X.; Killiny, N. RNA interference of two glutathione S-transferase genes, Diaphorina citri DcGSTe2 and DcGSTd1, increases the susceptibility of Asian citrus psyllid (Hemiptera: Liviidae) to the pesticides fenpropathrin and thiamethoxam. Pest Manag. Sci. 2018, 74, 638-647.

18. Tsai, J.H.; Liu, Y.H. Biology of Diaphorina citri (Homoptera: Psyllidae) on Four Host Plants. J. Econ. Entomol. 2000, 93, 17211725.

19. Amorós, M.E.; das Neves, V.P.; Rivas, F.; Buenahora, J.; Martini, X.; Stelinski, L.L.; Rossini, C. Response of Diaphorina citri (Hemiptera: Liviidae) to volatiles characteristic of preferred citrus hosts. Arthropod-Plant Interact. 2019, 13, 367-374.

20. Patt, J.M.; Meikle, W.G.; Mafra-Neto, A.; Sétamou, M.; Mangan, R.; Yang, C.; Malik, N.; Adamczyk, J.J. Multimodal cues drive host-plant assessment in asian citrus psyllid (Diaphorina citri). Environ. Entomol. 2011, 40, 1494-1502.

21. Qureshi, J.A.; Kostyk, B.C.; Stansly, P.A. Insecticidal Suppression of Asian Citrus Psyllid Diaphorina citri (Hemiptera: Liviidae) Vector of Huanglongbing Pathogens. PLoS ONE 2014, 9, 1-22.

22. Tofangsazi, N. Morales-Rodrigueza, A.; Daughertya, M.P.; Simmonsb, G.S.; Grafton-Cardwell, E.E. Residual toxicity of selected organic insecticides to Diaphorina citri (Hemiptera: Liviidae) and non-target effects on Tamarixia radiata (Hymenoptera: Eulophidae) in California. Crop Prot. 2018, 108, 62-70.

23. Naeen, A. Afzal, M.B.S.; Freed, S.; Hafeez, Faisal.; Zaka, S.M.; Ali, Q.; Anwar, H.M.Z.; Iftikhar, A.; Nawaz, M. First report of thiamethoxam resistance selection, cross resistance to various insecticides and realized heritability in Asian citrus psyllid Diaphorina citri from Pakistan. Crop Prot. 2019, 121, 11-17. 